\title{
The Impact of Antenna Pattern Frequency Dependence in Aperture Synthesis Microwave Radiometers
}

\author{
A. Camps, Senior Member, IEEE, I. Corbella, Member, IEEE, F. Torres, Member, IEEE, N. Duffo, Member, IEEE, \\ M. Vall-llosera, Member, IEEE, and M. Martin-Neira, Member, IEEE
}

\begin{abstract}
The effect of the frequency dependence of the antenna voltage patterns within the bandwidth of an aperture synthesis interferometric radiometer is studied and quantified using actual antenna voltage patterns measured at different frequencies for the first nine receivers of the Microwave Imaging Radiometer with Aperture Synthesis instrument aboard the European Space Agency's Soil Moisture and Ocean Salinity mission. A technique is proposed to mitigate this effect.
\end{abstract}

Index Terms-Antenna pattern, interferometer, microwave radiometer, radiometry.

\section{INTRODUCTION: THE VISIBILITY FUNCTION}

$\mathbf{S}$ OIL moisture and ocean salinity can be measured by microwave radiometry at L-band. To improve the achievable spatial resolution of real aperture radiometers and for the first time in Earth observation, the European Space Agency's (ESA) Soil Moisture and Ocean Salinity (SMOS) mission will use the concept of two-dimensional (2-D) aperture synthesis interferometric radiometry [1]. In this type of instrument, the actual measurements are the so-called samples of the "visibility function" $\left(V_{12}^{p q}\right)$ obtained from the cross-correlation products of the signals collected by each pair of receiving elements (named 1 and 2) at " $p$ " and " $q$ " polarizations, respectively. Assuming that the fourth Stokes parameter is negligible $\left(T_{4} \approx 0\right)$ so that $T_{y x}=T_{3}+j T_{4}=T_{x y}$, the equation that relates the samples of the visibility function $\left(V_{12}^{p q}\right)$ to the polarimetric brightness temperatures $\left(T_{p q}\right)$ in the antenna reference frame is given by [2], [3]

$$
\begin{aligned}
V_{12}^{x x}= & \frac{1}{\sqrt{\Omega_{1} \Omega_{2}}} \iint_{\xi^{2}+\eta^{2} \leq 1} \frac{1}{\sqrt{1-\xi^{2}-\eta^{2}}} \\
& \times\left[R_{x 1} R_{x 2}^{*}\left(T_{x x}-T_{\mathrm{rec}}\right)+\left(R_{x 1} C_{x 2}^{*}+C_{x 1} R_{x 2}^{*}\right) T_{y x}\right. \\
& \left.+C_{x 1} C_{x 2}^{*}\left(T_{\mathrm{yy}}-T_{\mathrm{rec}}\right)\right] \tilde{r}_{12}\left(-\frac{u_{12} \xi+v_{12} \eta}{f_{0}}\right) \\
& \times \exp \left(-j 2 \pi\left(u_{12} \xi+v_{12} \eta\right)\right) d \xi d \eta
\end{aligned}
$$

Manuscript received December 24, 2004; revised June 15, 2005. This work was supported in part by the Spanish Government under Grants MCYT and EU FEDER TIC2002-04451-C02-01 and in part by EADS-CASA Espacio in the frame of SMOS PLM Phase C/D activities DE03/C-181/PE1.

A. Camps, I. Corbella, F. Torres, N. Duffo, and M. Vall-llosera are with the Department of Signal Theory and Communications, Universitat Politècnica de Catalunya, Campus Nord, 08034 Barcelona, Spain (e-mail: camps@tsc.upc.es). M. Martin-Neira is with the European Space Research and Technology Centre, European Space Agency, 2200-AG Noordwijk, The Netherlands.

Digital Object Identifier 10.1109/TGRS.2005.854309

$$
\begin{aligned}
V_{12}^{y y}= & \frac{1}{\sqrt{\Omega_{1} \Omega_{2}}} \int_{\xi^{2}+\eta^{2} \leq 1} \frac{1}{\sqrt{1-\xi^{2}-\eta^{2}}} \\
& \times\left[C_{y 1} C_{y 2}^{*}\left(T_{x x}-T_{\mathrm{rec}}\right)+\left(R_{y 1} C_{y 2}^{*}+C_{y 1} R_{y 2}^{*}\right) T_{y x}\right. \\
& \left.+R_{y 1} R_{y 2}^{*}\left(T_{y y}-T_{\mathrm{rec}}\right)\right] \tilde{r}_{12}\left(-\frac{u_{12} \xi+v_{12} \eta}{f_{0}}\right) \\
& \times \exp \left(-j 2 \pi\left(u_{12} \xi+v_{12} \eta\right)\right) d \xi d \eta \\
V_{12}^{y x}= & \frac{1}{\sqrt{\Omega_{1} \Omega_{2}}} \iint_{\xi^{2}+\eta^{2} \leq 1} \frac{1}{\sqrt{1-\xi^{2}-\eta^{2}}} \\
& \times\left[C_{y 1} R_{x 2}^{*}\left(T_{x x}-T_{\mathrm{rec}}\right)+\left(R_{y 1} R_{x 2}^{*}+C_{y 1} C_{x 2}^{*}\right) T_{y x}\right. \\
& \left.+R_{y 1} C_{x 2}^{*}\left(T_{y y}-T_{\mathrm{rec}}\right)\right] \tilde{r}_{12}\left(-\frac{u_{12} \xi+v_{12} \eta}{f_{0}}\right) \\
& \times \exp \left(-j 2 \pi\left(u_{12} \xi+v_{12} \eta\right)\right) d \xi d \eta .
\end{aligned}
$$

In (1), we have the following.

- $T_{\text {rec }}$ is the receivers' physical temperature [2].

- $R_{p 1,2}(\xi, \eta)$ and $C_{p 1,2}(\xi, \eta)$ are the copolar (normalized) and cross-polar antenna radiation voltage patterns of elements 1 and 2 at $p$ polarization (" $p$ " $=$ " $x$ " or " $y$ ").

- $\Omega_{1,2}$ is the antenna solid angle.

- $\tilde{r}_{12}$ is the so-called fringe-washing function that accounts for spatial decorrelation effects

$$
\tilde{r}_{12}(\tau)=\frac{1}{\sqrt{B_{1} B_{2}}} \int_{0}^{\infty} H_{n 1}(f) \cdot H_{n 2}^{*}(f) \cdot \exp (j 2 \pi f \tau) d f
$$

which depends on the normalized receivers' frequency response $H_{n 1,2}(f)$; the transit time $\tau$ from a given direction $(\xi, \eta)$ to the pair of elements involved, and the noise bandwidth $B_{1,2}$ are defined as $\tau=-\left(u_{12} \xi+v_{12} \eta\right) / f_{0}$ and $B_{1,2}=\int_{0}^{\infty}\left|H_{n 1,2}(f)\right|^{2} d f$.

- $\left(u_{12}, v_{12}\right)$ is called the "baseline" and corresponds to the antenna spacing between elements 1 and 2 (located in the $\mathrm{X}-\mathrm{Y}$ plane) normalized to the wavelength at the central frequency $f_{0}$.

- $(\xi, \eta)=(\sin \theta \cos \phi, \sin \theta \sin \phi)$ are the director cosines with respect to the $\mathrm{X}$ and $\mathrm{Y}$ axis.

In this study, the impact of the frequency dependence of the antenna voltage patterns is analyzed. Section II deals with the radiometric accuracy degradation due to errors in the characterization of the antenna voltage patterns. Section III deals with the impact of the antenna pattern frequency dependence on the visibility samples, and finally Section IV estimates the impact on the radiometric accuracy if this frequency dependence is neglected. A method is proposed to minimize this effect. 


\section{IMPACT OF ANTENNA VOLTAGE PATTERN ERRORS ON THE RADIOMETRIC ACCURACY}

The impact of antenna characterization errors on the reconstructed brightness temperature image is studied at different levels of increasing complexity.

\section{A. Identical Antenna Patterns and Negligible Decorrelation Effects}

If all antenna copolar patterns are the same $\left(R_{p m}(\xi, \eta)=\right.$ $R_{p n}(\xi, \eta) \hat{=} R_{p}(\xi, \eta) \quad \forall m, n$, but are obviously measured with finite accuracy), cross-polar patterns can be neglected $\left(C_{p m}(\xi, \eta)=0 \forall m\right)$, and decorrelation effects are negligible $\left(\tilde{r}_{12}(\tau)=1\right)$, an inverse Fourier transform $\left(F T^{-1}\right)$ of the visibility samples can be used as image reconstruction algorithm

$$
\frac{T_{\mathrm{pp}}^{\prime}(\xi, \eta)}{\sqrt{1-\xi^{2}-\eta^{2}}} \frac{\left|R_{p}(\xi, \eta)\right|^{2}}{\Omega}=F T^{-1}[V(u, v)]
$$

where $T_{\mathrm{pp}}^{\prime}(\xi, \eta) \hat{=} T_{\mathrm{pp}}(\xi, \eta)-\mathrm{T}_{\mathrm{rec}}[(1 \mathrm{a})$ and (1b)]. In this case, since $F T^{-1}[V(u, v)]$ is equal to a constant value at each $(\xi, \eta)$ direction, it is straightforward to demonstrate that the relative error in $T_{\mathrm{pp}}^{\prime}(\xi, \eta)$ is the equal to the relative error in the measurement of the antenna pattern

$$
\frac{\Delta T_{\mathrm{pp}}^{\prime}}{T_{\mathrm{pp}}^{\prime}}=-\frac{\Delta D}{D}
$$

where $D(\xi, \eta)=4 \pi / \Omega \cdot|R(\xi, \eta)|^{2}$. Therefore, antenna pattern uncertainties scale with $T_{\mathrm{pp}}^{\prime}(\xi, \eta)=T_{\mathrm{pp}}(\xi, \eta)-\mathrm{T}_{\text {rec }}$ [except for $T_{\mathrm{yx}}^{\prime}(\xi, \eta)=T_{\mathrm{yx}}(\xi, \eta)$, which scale with $T_{y x}$, (1c)]. For an error of $\Delta T_{\mathrm{pp}}^{\prime}=1 \mathrm{~K}$ over $T_{\mathrm{pp}}^{\prime}=150 \mathrm{~K}, \Delta D / D=0.0067$, or equivalently $10 \log (1+\Delta D / D)=0.029 \mathrm{~dB}$. That is, for small antenna pattern errors, the sensibility to antenna pattern errors of the rms radiometric accuracy computed for all pixels in the instrument's field of view is roughly $35 \mathrm{~K} / \mathrm{dB}$ (Fig. 1, solid line).

\section{B. Different Antenna Patterns}

If antenna patterns are different and measured with finite accuracy, more sophisticated image reconstruction algorithms must be used. The formulation of the problem consists of the discretization of the set of linear equations given by (1a)-(1c) and casting them in matrix form [4], [5]

$$
\bar{V}=\overline{\bar{G}} \overline{\mathrm{T}}^{\prime} \text {. }
$$

Antenna pattern measurement errors translate into errors in the $\overline{\bar{G}}$ matrix elements, which in turn translate into errors in the reconstructed brightness temperature image. Depending on the size of the $\overline{\bar{G}}$ matrix and the computing resources, (5) can be inverted using the Moore-Penrose pseudoinverse as in [4], a conjugate-gradient algorithm as in [5], an iterative algorithm as in [6], a singular value decomposition, etc.

Numerical simulations neglecting the cross-polar patterns ${ }^{1}$ $\left(C_{p m}(\xi, \eta)=0 \forall m\right)$ are shown in Fig. 1 using (circled crosses) or not (circled dots) the available redundant baselines (different antenna pairs leading to the same $(u, v)$ value) present in the

\footnotetext{
${ }^{1}$ The impact of neglecting the cross-polar patterns has been studied in [3] and found to be $\leq 0.2 \mathrm{~K}$ for a cross-polar level at boresight of $-30 \mathrm{~dB}$ approximately, and $-25 \mathrm{~dB}$ worst case at the border of the alias-free field of view.
}

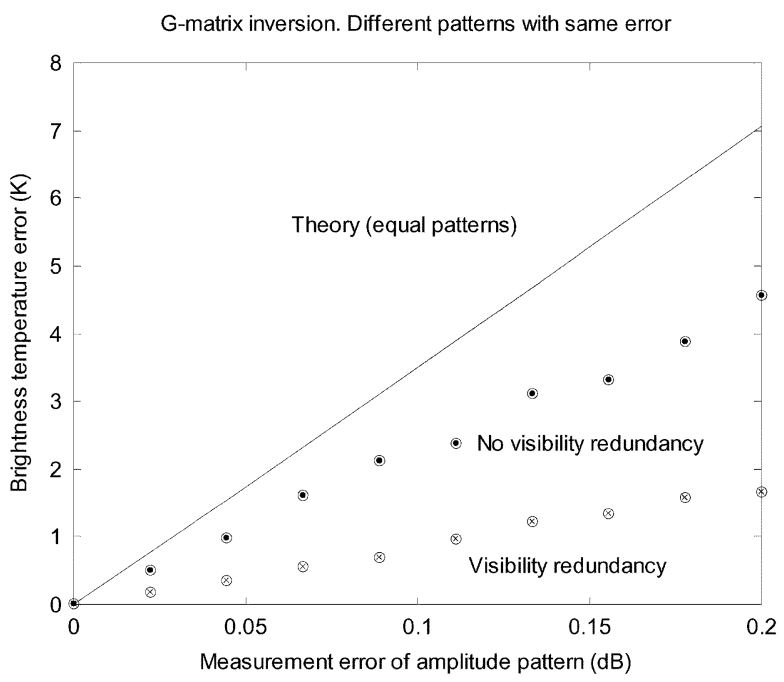

Fig. 1. Root mean squared (rms) radiometric accuracy due to antenna pattern measurement errors (amplitude $[\mathrm{dB}]$ ): equal antenna patterns (solid line), different antenna patterns without visibility redundancy (circled dots), and with visibility redundancy (circled crosses). Radiometric accuracy is computed as the rms value of the radiometric accuracy for pixels within the instrument's field of view. $T_{\mathrm{pp}}^{\prime}=150 \mathrm{~K}$.

array. As it can be appreciated, independent errors in different antennas have an averaging effect, reducing the impact on the retrieval error down to an rms radiometric accuracy sensibility of $9.12 \mathrm{~K} / \mathrm{dB}$ (Fig. 1, circled crosses) for pixels in the instrument's field of view. Similarly, for small antenna pattern phase errors the radiometric accuracy degrades and the associated sensibility is $1.11 \mathrm{~K} / 0$ for $T_{\mathrm{pp}}^{\prime}=150 \mathrm{~K}$ [7].

\section{IMPACT OF THE ANTENNA VOLTAGE PATTERN FREQUENCY DEPENDENCE IN THE VISIBILITY FUNCTION}

In the derivation of (1) all studies have always implicitly assumed that the only frequency-dependent magnitudes are the normalized receivers' frequency responses $\left(H_{\mathrm{n}}(f)\right)$. However, the antenna voltage patterns do also present a small variation within the receivers' bandwidth $\left(R_{x, y 1,2}(\xi, \eta, f)\right.$ and $\left.C_{x, y 1,2}(\xi, \eta, f)\right)$ and actually the terms within brackets in (1) should appear inside the integral of the fringe-washing function (2). To simplify the notation, only the frequency dependence will be made explicit in each product of antenna patterns $\left(R_{x, y 1,2}\right.$ or $\left.C_{x, y 1,2}\right)$. In this case, (1) can be rewritten as ${ }^{2}$

$$
\begin{aligned}
V_{12}^{x x}= & \frac{1}{\sqrt{\Omega_{1} \Omega_{2}}} \int_{\xi^{2}+\eta^{2} \leq 1} \frac{1}{\sqrt{1-\xi^{2}-\eta^{2}}} \\
& \times\left\{\frac { 1 } { \sqrt { B _ { 1 } B _ { 2 } } } \int _ { 0 } ^ { \infty } \left[R_{x 1} R_{x 2}^{*}\left(T_{x x}-T_{\mathrm{rec}}\right)\right.\right. \\
& \left.+\left(R_{x 1} C_{x 2}^{*}+C_{x 1} R_{x 2}^{*}\right) T_{y x}+C_{x 1} C_{x 2}^{*}\left(T_{y y}-T_{\mathrm{rec}}\right)\right] \\
& \left.\cdot H_{n 1}(f) \cdot H_{n 2}^{*}(f) \cdot \exp (j 2 \pi f \tau) d f\right\} d \xi d \eta
\end{aligned}
$$

${ }^{2}$ In (6), it is implicitly assumed that $\Omega_{m}$ is constant. To include its frequency dependence, it suffices to replace $R_{p m}$ and $C_{p m}$ by $R_{p m} / \sqrt{\Omega_{m}}$ and $C_{p m} / \sqrt{\Omega_{m}}$. 

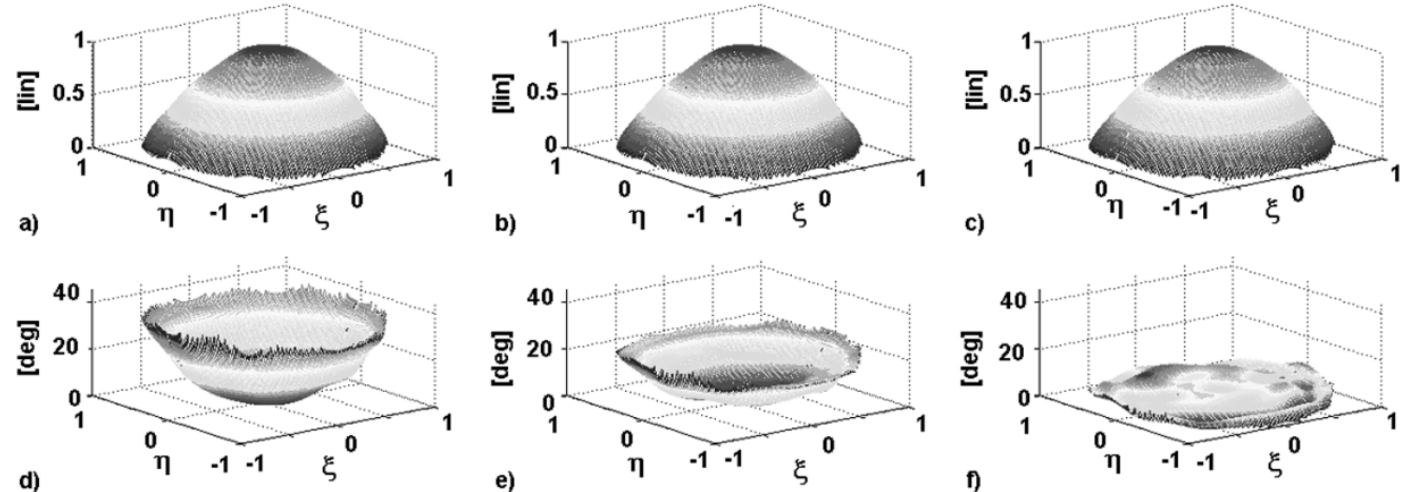

Fig. 2. Frequency dependence of normalized antenna copolar voltage number $1 F_{1}(\xi, \eta, f)=R_{1}(\xi, \eta, f)$ as provided by EADS-CASA Antenna Pattern Measurements (CD-ROM, July 2002). (a)-(c) Amplitude and (d)-(f) phase at (a), (d) $f_{0}-B / 2=1403 \mathrm{MHz}$, (b), (e) $f_{0}=1413 \mathrm{MHz},(\mathrm{c}),(\mathrm{f}) f_{0}+B / 2=$ $1423 \mathrm{MHz}$.
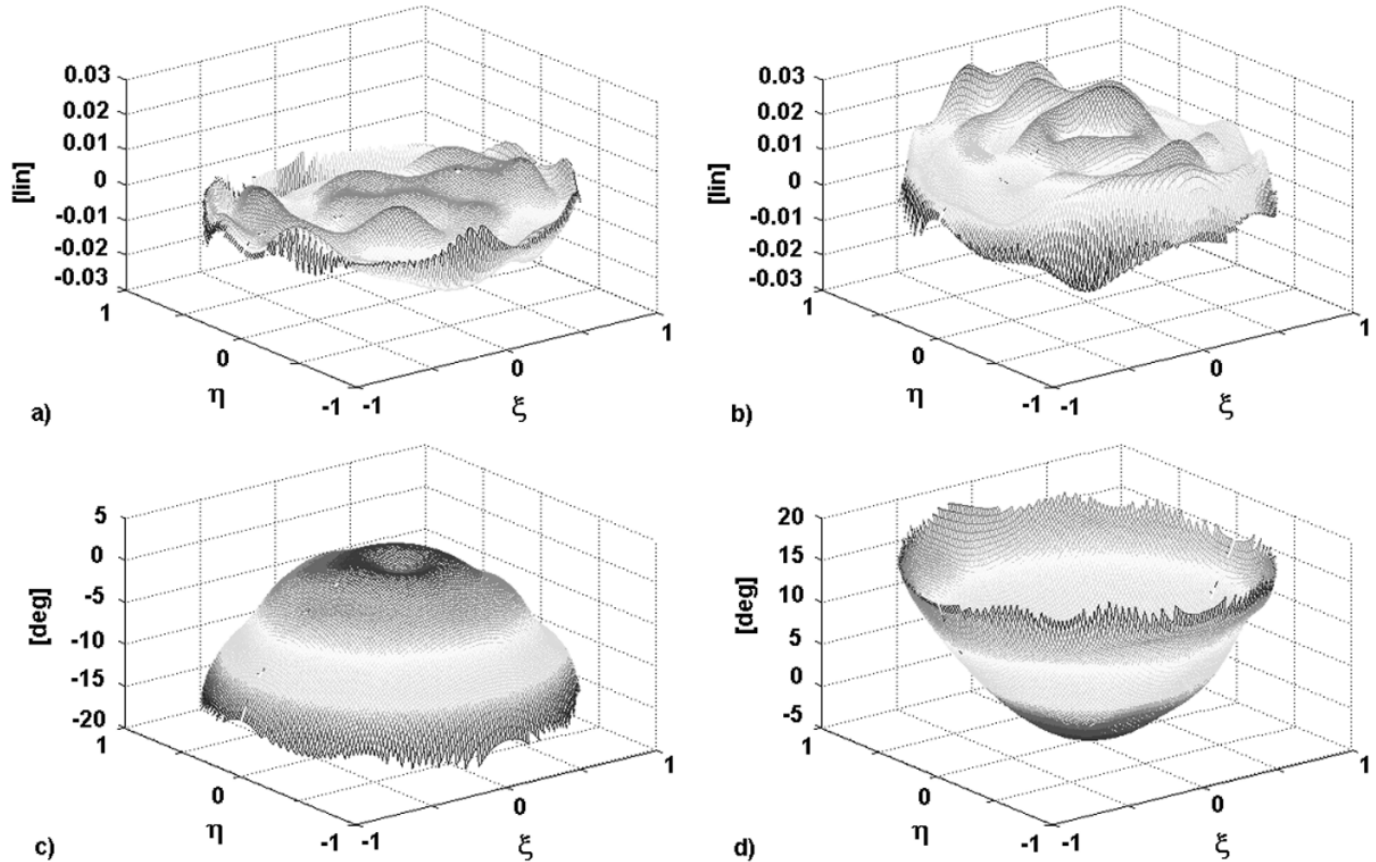

Fig. 3. Frequency variation of normalized antenna copolar voltage number $1 F_{1}(\xi, \eta, f)=R_{1}(\xi, \eta, f)$ as provided by EADS-CASA Antenna Pattern Measurements (CD-ROM, July 2002). (a), (b) Amplitude difference and (c), (d) phase difference at (a), (c) $f_{0}-B / 2=1403 \mathrm{MHz}$ and $f_{0}=1413 \mathrm{MHz}$, and (b), (d) $f_{0}=1413 \mathrm{MHz}$ and $f_{0}+B / 2=1423 \mathrm{MHz}$.

$$
\begin{aligned}
V_{12}^{\mathrm{yy}}= & \frac{1}{\sqrt{\Omega_{1} \Omega_{2}}} \iint_{\xi^{2}+\eta^{2} \leq 1} \frac{1}{\sqrt{1-\xi^{2}-\eta^{2}}} \\
& \times\left\{\frac { 1 } { \sqrt { B _ { 1 } B _ { 2 } } } \int _ { 0 } ^ { \infty } \left[C_{y 1} C_{y 2}^{*}\left(T_{x x}-T_{\mathrm{rec}}\right)\right.\right. \\
& \left.+\left(R_{y 1} C_{y 2}^{*}+C_{y 1} R_{y 2}^{*}\right) T_{y x}+R_{y 1} R_{y 2}^{*}\left(T_{y y}-T_{\mathrm{rec}}\right)\right] \\
& \left.\cdot H_{n 1}(f) \cdot H_{n 2}^{*}(f) \cdot \exp (j 2 \pi f \tau) d f\right\} d \xi d \eta
\end{aligned}
$$$$
V_{12}^{y x}=\frac{1}{\sqrt{\Omega_{1} \Omega_{2}}} \int_{\xi^{2}+\eta^{2} \leq 1} \frac{1}{\sqrt{1-\xi^{2}-\eta^{2}}}
$$$$
\times\left\{\frac { 1 } { \sqrt { B _ { 1 } B _ { 2 } } } \int _ { 0 } ^ { \infty } \left[C_{y 1} R_{x 2}^{*}\left(T_{x x}-T_{\text {rec }}\right)\right.\right.
$$

$$
\begin{aligned}
& +\left(R_{y 1} R_{x 2}^{*}+C_{y 1} C_{x 2}^{*}\right) T_{y x} \\
& \left.+R_{y 1} C_{x 2}^{*}\left(T_{y y}-T_{\mathrm{rec}}\right)\right] \cdot H_{n 1}(f) \\
& \left.\cdot H_{n 2}^{*}(f) \cdot \exp (j 2 \pi f \tau) d f\right\} d \xi d \eta .
\end{aligned}
$$

At L-band the available relative bandwidth is about $2 \%(B=$ $\left.27 \mathrm{MHz}, f_{0}=1413.5 \mathrm{MHz}\right)$, therefore at each $(\xi, \eta)$ direction the antenna voltage patterns' variation with frequency is small. For the first Microwave Imaging Radiometer with Aperture Synthesis (MIRAS) SMOS antennas it is actually $<3 \%$ in amplitude and $<15^{\circ}$ in phase, as shown in Figs. 2 and 3. Therefore, (6a)-(6c) can each be split into four integrals containing a product of the antenna voltage patterns $R_{x, y 1,2}$ or $C_{x, y 1,2}\left(R_{p 1} R_{q 2}^{*}, R_{p 1} C_{q 2}^{*}, C_{p 1} R_{q 2}^{*}\right.$, and $\left.C_{p 1} C_{q 2}^{*}\right)$ which, for the sake of simplicity, will be noted as $F_{p 1}(f) \cdot F_{q 2}^{*}(f)$. Since the antenna voltage pattern frequency dependence is small, at each $(\xi, \eta)$ direction, each of the integrals versus frequency can be 
evaluated using a Taylor series of the product of the antenna voltage patterns around $f \approx f_{0}\left(f=f_{0}+f^{\prime}, f^{\prime} \approx 0\right)$, as in (7), shown at the bottom of the page, which can be expressed in terms of the derivatives of the fringe-washing function

$$
\begin{aligned}
& e^{j 2 \pi t_{0} \tau}\left\{F_{p 1}\left(f_{0}\right) \cdot F_{q 2}^{*}\left(f_{0}\right) \tilde{r}_{12}(\tau)\right. \\
& +\left.\frac{\partial\left[F_{p 1}\left(f^{\prime}+f_{0}\right) \cdot F_{q 2}^{*}\left(f^{\prime}+f_{0}\right)\right]}{\partial f^{\prime}}\right|_{f^{\prime}=0} \cdot \frac{1}{2 \pi} \frac{\partial \tilde{r}_{12}(\tau)}{\partial \tau} \\
& \left.+\left.\frac{1}{2} \frac{\partial^{2}\left[F_{p 1}\left(f^{\prime}+f_{0}\right) \cdot F_{q 2}^{*}\left(f^{\prime}+f_{0}\right)\right]}{\partial f^{\prime 2}}\right|_{f^{\prime}=0} \cdot \frac{1}{(2 \pi)^{2}} \frac{\partial^{2} \tilde{r}_{12}(\tau)}{\partial \tau^{2}}\right\} .
\end{aligned}
$$

The actual shape of the receivers' frequency response is not rectangular. However, around $\tau=0(|\tau| \leq 18 \mathrm{~ns})$, the fringewashing function has a sinc-like shape for the amplitude, and the phase can be very well approximated by a second-order polynomial

$$
\tilde{r}_{12}(\tau)=A \operatorname{sinc}(B(\tau-C)) e^{j\left(D \tau^{2}+E \tau\right)}
$$

where $A$ being different from 1 is an amplitude error, $B$ is the equivalent noise bandwidth for a baseline, $C$ is the effective difference between the delays of the two channels involved in the correlation, $E=2 \pi f_{\mathrm{IF}}$ is due to a frequency mismatch between receivers and the nominal center frequency, and $D$ accounts for a distortion of the phase response. Note that the phase of (9) at $\tau=0$ is zero since it is already calibrated by noise injec- tion [8]. Some recent measurements ${ }^{3}$ performed with the first LICEF units show the goodness of the above approximation, with the following representative values for the parameters: $A=$ $1.001, B=18 \mathrm{MHz}, C=-1.5 \mathrm{~ns}, D=0.510^{-3} \circ / \mathrm{ns}=2.6$ $\mathrm{KHz} / \mathrm{ns}$, and $E=-0.24^{\circ} / \mathrm{ns}=1.3 \mathrm{KHz}$ (Fig. 4).

To evaluate the impact of the frequency dependence of the antenna radiation voltage patterns, the derivatives of (9) at $\tau=0$ are computed and substituted in (8)

$$
\left.\tilde{r}_{12}(\tau)\right|_{\tau=0}=A \operatorname{sinc}(B \cdot C)
$$

$$
\begin{gathered}
\left.\frac{\partial \tilde{r}_{12}(\tau)}{\partial \tau}\right|_{\tau=0}=\frac{A}{C}[-\cos (\pi \cdot B \cdot C)+(1+j \cdot E \cdot C) \operatorname{sinc}(B \cdot C)] \\
\approx j A \cdot E \cdot \operatorname{sinc}(B \cdot C)
\end{gathered}
$$

$$
\begin{aligned}
\left.\frac{\partial^{2} \tilde{r}_{12}(\tau)}{\partial \tau^{2}}\right|_{\tau=0}=\frac{A}{C}\left\{\left[-C(\pi B)^{2}-E^{2} \cdot C+\frac{2}{C}+j 2(E+C \cdot D)\right]\right. \\
\left.\quad \times \operatorname{sinc}(B \cdot C)-2\left(\frac{1}{C}+j \cdot E\right) \cos (\pi \cdot B \cdot C)\right\} \\
\approx A\left[(\pi B)^{2}-E^{2}+j 2 D\right] \operatorname{sinc}(B \cdot C) \\
\approx A \cdot \pi^{2} \cdot B^{2} \cdot \operatorname{sinc}(B \cdot C)
\end{aligned}
$$

In addition, the derivatives of the product of the antenna voltage patterns can be numerically approximated by (11), shown at the bottom of the next page. Inserting (10) and (11) in (8) leads to (12), shown at the bottom of the next page, where

- the exponential term with $\tau=-\left(u_{12} \xi+v_{12} \eta\right) / f_{0}$ corresponds to the exponential term in (1);

${ }^{3}$ Measurements performed by MIER Comunicaciones SA and processed by the authors in the frame of the MIRAS/SMOS phase C/D project.

$$
\begin{aligned}
& \frac{1}{\sqrt{B_{1} B_{2}}} \int_{0}^{\infty} F_{p 1}(f) \cdot F_{q 2}^{*}(f) \cdot H_{n 1}(f) H_{n 2}^{*}(f) \cdot \exp (j 2 \pi f \tau) d f \approx \frac{1}{\sqrt{B_{1} B_{2}}} \int_{0}^{\infty}\left\{F_{p 1}\left(f_{0}\right) \cdot F_{q 2}^{*}\left(f_{0}\right)+\left.\frac{\partial\left[F_{p 1}(f) \cdot F_{q 2}^{*}(f)\right]}{\partial f}\right|_{f=f_{0}}\left(f-f_{0}\right)\right. \\
& \left.+\left.\frac{1}{2} \frac{\partial^{2}\left[F_{p 1}(f) \cdot F_{q 2}^{*}(f)\right]}{\partial f^{2}}\right|_{f=f_{0}}\left(f-f_{0}\right)^{2}\right\} \cdot H_{n 1}(f) \cdot H_{n 2}^{*}(f) \cdot \exp (j 2 \pi f \tau) d f \\
& \underset{\substack{f=f^{\prime}+f_{0} \\
d f=d f^{\prime}}}{e^{j 2 \pi f_{0} \tau}} \int_{-f_{0}}^{\infty}\left\{F_{p 1}\left(f_{0}\right) \cdot F_{q 2}^{*}\left(f_{0}\right)+\left.\frac{\partial\left[F_{p 1}\left(f^{\prime}+f_{0}\right) \cdot F_{q 2}^{*}\left(f^{\prime}+f_{0}\right)\right]}{\partial f^{\prime}}\right|_{f^{\prime}=0} f^{\prime}\right. \\
& \left.+\left.\frac{1}{2} \frac{\partial^{2}\left[F_{p 1}\left(f^{\prime}+f_{0}\right) \cdot F_{q 2}^{*}\left(f+f_{0}\right)\right]}{\partial f^{\prime 2}}\right|_{f=0} f^{\prime 2}\right\} \cdot H_{n 1}\left(f^{\prime}+f_{0}\right) \cdot H_{n 2}^{*}\left(f^{\prime}+f_{0}\right) \cdot \exp \left(j 2 \pi f^{\prime} \tau\right) d f^{\prime} \\
& =\frac{e^{j 2 \pi f_{0} \tau}}{\sqrt{B_{1} B_{2}}}\left\{F_{p 1}\left(f_{0}\right) \cdot F_{q 2}^{*}\left(f_{0}\right) \int_{-f_{0}}^{\infty} H_{n 1}\left(f^{\prime}+f_{0}\right) \cdot H_{n 2}^{*}\left(f^{\prime}+f_{0}\right) \cdot \exp \left(j 2 \pi f^{\prime} \tau\right) d f^{\prime}+\left.\frac{\partial\left[F_{p 1}\left(f^{\prime}+f_{0}\right) \cdot F_{q 2}^{*}\left(f^{\prime}+f_{0}\right)\right]}{\partial f^{\prime}}\right|_{f^{\prime}=0}\right. \\
& \times \int_{-f_{0}}^{\infty} f^{\prime} \cdot H_{n 1}\left(f^{\prime}+f_{0}\right) \cdot H_{n 2}^{*}\left(f^{\prime}+f_{0}\right) \cdot \exp \left(j 2 \pi f^{\prime} \tau\right) d f^{\prime}+\left.\frac{1}{2} \frac{\partial^{2}\left[F_{p 1}\left(f^{\prime}+f_{0}\right) \cdot F_{q 2}^{*}\left(f^{\prime}+f_{0}\right)\right]}{\partial f^{\prime 2}}\right|_{f^{\prime}=0} \\
& \left.\times \int_{-f_{0}}^{\infty} f^{\prime 2} \cdot H_{n 1}\left(f^{\prime}+f_{0}\right) \cdot H_{n 2}^{*}\left(f^{\prime}+f_{0}\right) \cdot \exp \left(j 2 \pi f^{\prime} \tau\right) d f^{\prime}\right\}
\end{aligned}
$$



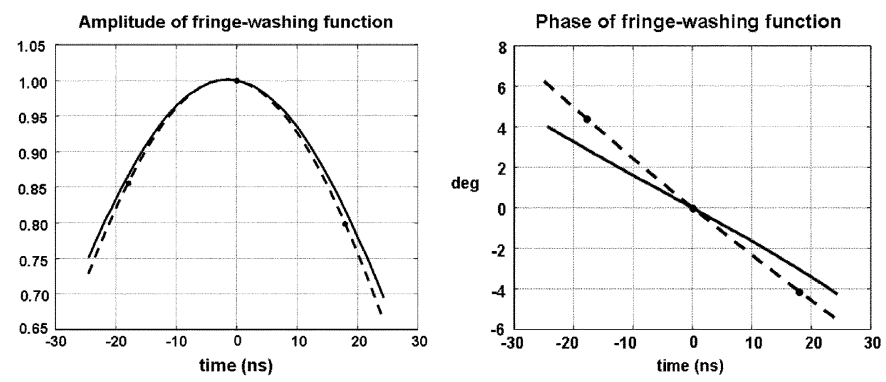

a)

b)

Fig. 4. Fringe-washing functions computed for a representative pair of LICEF (MIRAS/SMOS receivers) [5]: from measured receiver frequency responses (solid line) and by the three delay technique (dots) and approximated by a sinc function for the amplitude and a second-order polynomial for the phase (dashed line). The phase slope error is attributed to a time delay introduced in the measurement of the frequency response.

- the term $A \cdot \operatorname{sinc}(B \cdot C)$ corresponds to the amplitude of the fringe-washing function at the origin;

- the first term within the brackets corresponds to the sum of the zeroeth and the second-order terms and corresponds to the weighted average of the products of the antenna voltage patterns at $f_{0}-B / 2, f_{0}$ and $f_{0}+B / 2$ with weights $1 / 4$, $1 / 2$, and $1 / 4$, respectively;

- the last term within the brackets is the first-order term and accounts for asymmetries in the antenna patterns products around the central frequency $f_{0}$, and it is equivalent mainly to a phase error.

Since $E / B<<1,(12)$ can be approximated by the term within the brackets in (12)

$$
\begin{gathered}
e^{j 2 \pi f_{0} \tau} A \cdot \operatorname{sinc}(B \cdot C)\left[\frac{1}{4} F_{p 1}\left(f_{0}+B / 2\right)\right. \\
\cdot F_{q 2}^{*}\left(f_{0}+B / 2\right)+\frac{1}{2} F_{p 1}\left(f_{0}\right) \cdot F_{n q 2}^{*}\left(f_{0}\right) \\
\left.+\frac{1}{4} F_{p 1}\left(f_{0}-B / 2\right) \cdot F_{q 2}^{*}\left(f_{0}-B / 2\right)\right] .
\end{gathered}
$$

If the antenna pattern frequency dependence were neglected, an error will be committed. This error can be associated to an antenna voltage pattern error given in (14), shown at the bottom of the page. Fig. 5 shows the magnitude of this error computed for antennas \#2 and \#4 at Y-polarization, except for a 1/4 scale factor. The rms values of the first and second-order error terms associated to each antenna pair ${ }^{4}$ are computed for $\xi^{2}+\eta^{2} \leq 1$. Numerical results are summarized in Tables I and II indicating the minimum, mean, and maximum rms error at X- and Y-polarizations, both for the real and imaginary parts.

${ }^{4}$ Antenna patterns measured by EADS-CASA, CD-ROM July 2002

$$
\begin{aligned}
&\left.F_{p 1}\left(f^{\prime}+f_{0}\right) \cdot F_{q 2}^{*}\left(f^{\prime}+f_{0}\right)\right|_{f^{\prime}=0}=F_{p 1}\left(f_{0}\right) \cdot F_{q 2}^{*}\left(f_{0}\right) \\
&\left.\frac{\left.\partial F_{p 1}\left(f^{\prime}+f_{0}\right) \cdot F_{n q 2}^{*}\left(f^{\prime}+f_{0}\right)\right]}{\partial f^{\prime}}\right|_{f^{\prime}=0} \approx \frac{F_{p 1}\left(f_{0}+B / 2\right) \cdot F_{q 2}^{*}\left(f_{0}+B / 2\right)-F_{p 1}\left(f_{0}-B / 2\right) \cdot F_{q 2}^{*}\left(f_{0}-B / 2\right)}{B} \\
&\left.\frac{\partial^{2}\left[F_{p 1}\left(f^{\prime}+f_{0}\right) \cdot F_{q 2}^{*}\left(f^{\prime}+f_{0}\right)\right]}{\partial f^{\prime 2}}\right|_{f^{\prime}=0} \approx \frac{F_{p 1}\left(f_{0}+B / 2\right) \cdot F_{q 2}^{*}\left(f_{0}+B / 2\right)-2 F_{p 1}\left(f_{0}\right) \cdot F_{q 2}^{*}\left(f_{0}\right)+F_{p 1}\left(f_{0}-B / 2\right) \cdot F_{q 2}^{*}\left(f_{0}-B / 2\right)}{2(B / 2)^{2}}
\end{aligned}
$$

$$
\begin{aligned}
& e^{j 2 \pi f_{0} \tau} A \cdot \operatorname{sinc}(B \cdot C)\left\{\frac{F_{p 1}\left(f_{0}+B / 2\right) \cdot F_{q 2}^{*}\left(f_{0}+B / 2\right)+2 F_{p 1}\left(f_{0}\right) \cdot F_{q 2}^{*}\left(f_{0}\right)+F_{p 1}\left(f_{0}-B / 2\right) \cdot F_{q 2}^{*}\left(f_{0}-B / 2\right)}{4}\right. \\
& \left.+j \frac{E}{2 \pi} \cdot \frac{F_{p 1}\left(f_{0}+B / 2\right) \cdot F_{q 2}^{*}\left(f_{0}+B / 2\right)-F_{p 1}\left(f_{0}-B / 2\right) \cdot F_{q 2}^{*}\left(f_{0}-B / 2\right)}{B}\right\} \\
= & e^{j 2 \pi f_{0} \tau} A \cdot \operatorname{sinc}(B \cdot C)\left\{\left[\frac{1}{4} F_{p 1}\left(f_{0}+B / 2\right) \cdot F_{q 2}^{*}\left(f_{0}+B / 2\right)+\frac{1}{2} F_{p 1}\left(f_{0}\right) \cdot F_{q 2}^{*}\left(f_{0}\right)+\frac{1}{4} F_{p 1}\left(f_{0}-B / 2\right) \cdot F_{q 2}^{*}\left(f_{0}-B / 2\right)\right]\right. \\
& \left.+j \frac{E}{2 \pi} \cdot \frac{F_{p 1}\left(f_{0}+B / 2\right) \cdot F_{q 2}^{*}\left(f_{0}+B / 2\right)-F_{p 1}\left(f_{0}-B / 2\right) \cdot F_{q 2}^{*}\left(f_{0}-B / 2\right)}{B}\right\}
\end{aligned}
$$

$$
\begin{array}{r}
\left\{\frac{1}{4} F_{p 1}\left(f_{0}+B / 2\right) \cdot F_{q 2}^{*}\left(f_{0}+B / 2\right)+\frac{1}{2} F_{p 1}\left(f_{0}\right) F_{n q 2}^{*}\left(f_{0}\right)+\frac{1}{4} F_{p 1}\left(f_{0}-B / 2\right) \cdot F_{q 2}^{*}\left(f_{0}-B / 2\right)\right\}-F_{p 1}\left(f_{0}\right) \cdot F_{n q 2}^{*}\left(f_{0}\right) \\
=\frac{1}{4}\left\{F_{p 1}\left(f_{0}+B / 2\right) \cdot F_{q 2}^{*}\left(f_{0}+B / 2\right)-2 F_{p 1}\left(f_{0}\right) \cdot F_{n q 2}^{*}\left(f_{0}\right)+F_{p 1}\left(f_{0}-B / 2\right) F_{q 2}^{*}\left(f_{0}-B / 2\right)\right\}
\end{array}
$$

$$
\begin{aligned}
F_{n 1}\left(\xi, \eta, f_{0}\right) F_{n 2}^{*}\left(\xi, \eta, f_{0}\right) \rightarrow & \frac{1}{4} F_{n 1}\left(\xi, \eta, f_{0}-\right. \\
& B / 2) F_{n 2}^{*}\left(\xi, \eta, f_{0}-B / 2\right) \\
& +\frac{1}{2} F_{n 1}\left(\xi, \eta, f_{0}\right) F_{n 2}^{*}\left(\xi, \eta, f_{0}\right)+\frac{1}{4} F_{n 1}\left(\xi, \eta, f_{0}+B / 2\right) F_{n 2}^{*}\left(\xi, \eta, f_{0}+B / 2\right)
\end{aligned}
$$



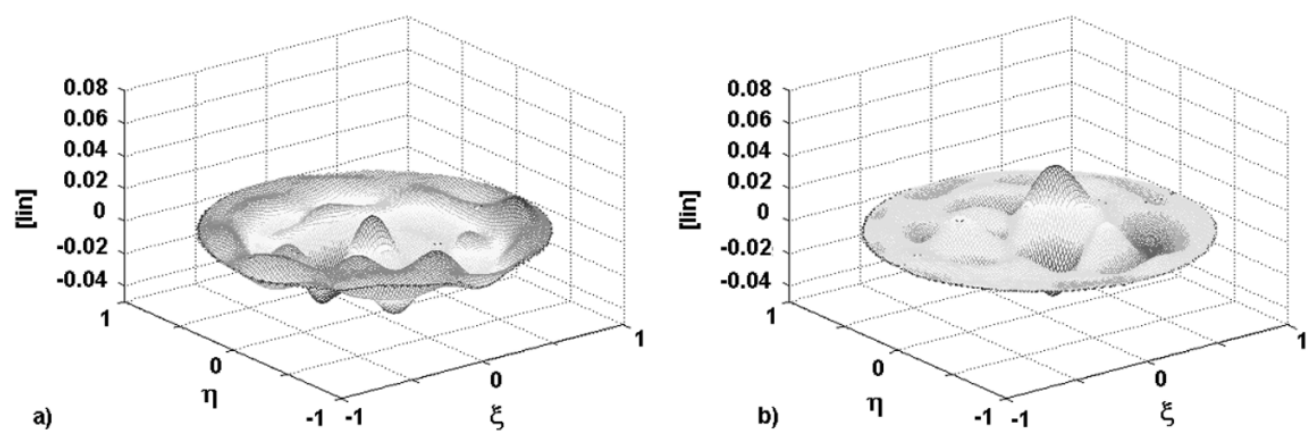

Fig. 5. (a) Real and (b) imaginary parts of $F_{M}\left(\xi, \eta, f_{0}-B / 2\right) F_{N}^{*}\left(\xi, \eta, f_{0}-B / 2\right) \quad-\quad 2 F_{M}\left(\xi, \eta, f_{0}\right) F_{N}^{*}\left(\xi, \eta, f_{0}\right) \quad+$ $F_{M}\left(\xi, \eta, f_{0}+B / 2\right) F_{N}^{*}\left(\xi, \eta, f_{0}+B / 2\right)$, for the copolar patterns $F_{p}(\xi, \eta, f)=R_{p}(\xi, \eta, f)$ of antennas $M=2$ and $N=4$, at $f_{0}-B / 2=1403$ $\mathrm{MHz}, f_{0}=1413 \mathrm{MHz}$, and $f_{0}+B / 2=1423 \mathrm{MHz}$.

TABLE I

Minimum, Mean, and MaXimum rms ERror Associated to the SeCond TERM IN (11) FOR $B=20 \mathrm{MHz}, f_{0}=1413 \mathrm{MHz}$, AND $E=1.3 \mathrm{KHz}$ (VAlues Must Be Multiplied By $10^{-6}$ )

\begin{tabular}{lllllll} 
& \multicolumn{1}{c}{$\begin{array}{l}X-\text { pol } \\
\text { min }\end{array}$} & mean & $\max$ & $\begin{array}{l}Y \text {-pol } \\
\text { min }\end{array}$ & mean & $\max$ \\
\hline real part & 0.084 & 0.122 & 0.171 & 0.101 & 0.134 & 0.194 \\
imaginary part & 0.000 & 0.139 & 0.269 & 0.000 & 0.158 & 0.317 \\
\hline
\end{tabular}

TABLE II

Minimum, Mean, AND MAXIMUM rms ERROR ASSOCIATED to THE Third Term IN (11) (VAlues Must Be MultiPlied By $10^{-2}$ )

\begin{tabular}{lllllll} 
& & & & & & \\
& X-pol & & & & & \\
& $\min$ & mean & $\max$ & $\min$ & mean & $\max$ \\
\hline real part & 0.542 & 1.067 & 1.408 & 0.934 & 1.110 & 1.290 \\
imaginary part & 0.000 & 1.266 & 3.224 & 0.000 & 0.570 & 0.795 \\
\hline
\end{tabular}

\section{IMPACT OF THE ANTENNA VOLTAGE PATTERN FREQUENCY DEPENDENCE IN THE RADIOMETRIC ACCURACY}

The impact on the rms radiometric accuracy of neglecting the antenna pattern frequency dependence can be estimated as follows.

- For the product of the normalized antenna patterns $\left(F_{p 1}(f) \cdot F_{q 2}^{*}(f)\right)$ :

- the average rms error is $<1.07 \%$ for the real part, and $<1.27 \%$ for the imaginary part, which translates into an rms amplitude error of $\sqrt{(1+0.0107)^{2}+0.0127^{2}}-$ $1=0.0107=1.07 \%$ (or equivalently 20 . $\log (1+0.0107)=0.092 \mathrm{~dB})$

- the average rms phase error is $<\tan (0.0127 / 1.0107)=0.72 \%$.

- Assuming that the associated error is the same for all patterns, the amplitude and phase rms errors associated with each pattern are: $1.07 \% / \sqrt{ } 2=0.76 \%$ (or equivalently $20 \cdot \log (1+0.0076)=0.065 \mathrm{~dB})$ and $0.72^{\circ} / \sqrt{ } 2=0.51^{\circ}$, which translate into a degradation of the radiometric accuracy of (Section II-B):

$-0.065 \mathrm{~dB} \cdot 9.12 \mathrm{~K} / \mathrm{dB}=0.59 \mathrm{~K}$;

$-0.51^{\circ} \cdot 1.11 \mathrm{~K} /{ }^{\circ}=0.57 \mathrm{~K}$.

which should be added quadratically to other error terms in the radiometric accuracy error budget. In the MIRAS/SMOS case the current total rms radiometric accuracy estimate is $\Delta T_{\mathrm{pp}}^{\prime}=$ $2.40 \mathrm{~K}$ (Table II of [9]), which will degrade up to $\Delta T_{\mathrm{pp}}^{\mathrm{pp}}=$ $2.54 \mathrm{~K}$ if the antenna voltage pattern frequency dependence is neglected.
However, if each of the products of the antenna voltage patterns used in the image reconstruction algorithms (1) are replaced by the weighted average given in (15), shown at the bottom of the previous page [term within brackets in (13)]. The residual impact of the antenna pattern frequency dependence on the radiometric accuracy (pixel bias) is negligible, since error terms in Table I are 4 orders of magnitude smaller than those in Table II.

\section{CONCLUSION}

The impact of antenna voltage pattern errors has been studied, including the impact of the frequency dependence, which has been evaluated using the first nine antenna voltage patterns measured by EADS-CASA (July 2002) at 1403, 1413, and 1423 $\mathrm{MHz}$ for the MIRAS/SMOS receivers. If each pair of antenna voltage pattern products in (1) are replaced by the weighted average of the antenna voltage patterns measured at $f_{0}-B / 2, f_{0}$, and $f_{0}+B / 2$ with weights $1 / 4,1 / 2$, and $1 / 4$, the impact on the rms radiometric accuracy is negligible. However, if only the patterns at the central frequency are used in the formulation of the image reconstruction the rms radiometric accuracy will degrade from 2.40 to $2.54 \mathrm{~K}$.

\section{ACKNOWLEDGMENT}

The authors thank three anonymous reviewers for their comments to improve this work.

\section{REFERENCES}

[1] ESA, "ESA's Water Mission: SMOS," Eur. Space Agency, Noordwijk, The Netherlands, ESA Pub. 92-9092-735-6. [Online]. Available: http://esamultimedia.esa.int/docs/br_224.pdf.

[2] I. Corbella, N. Duffo, M. Vall-1lossera, A. Camps, and F. Torres, "The visibility function in interferometric aperture synthesis radiometry," IEEE Trans. Geosci. Remote Sens., vol. 42, no. 8, pp. 1677-1682, Aug. 2004.

[3] A. Camps, I. Corbella, F. Torres, M. Vall-llossera, and N. Duffo, "Polarimetric formulation of the visibility function equation including crosspolar antenna patterns," IEEE Geosci. Remote Sens. Lett., vol. 2, no. 3, pp. 292-295, Jul. 2005.

[4] A. B. Tanner and C. T. Swift, "Calibration of a synthetic aperture radiometer," IEEE Trans. Geosci. Remote Sens., vol. 31, no. 1, pp. 257-267, Jan. 1993.

[5] R. Tomás, "Algoritmos de reconstrucción de imagen en radiometría por síntesis de apertura," School Telecommun, Eng., Tech. Univ. Catalonia, Barcelona, Spain, Final Project Rep., 2002. 
[6] A. Camps, J. Bará, F. Torres, and I. Corbella, "Extension of the CLEAN technique to the microwave imaging of continuous thermal sources by means of aperture synthesis radiometers," Progr. Electromagn. Res., vol. PIER 18, pp. 67-83, Jan. 1998.

[7] A. Camps, J. Bará, F. Torres, I. Corbella, and J. Romeu, "Impact of antenna errors on the radiometric accuracy of large aperture synthesis radiometers," Radio Sci., vol. 32, no. 2, pp. 657-668, Mar.-Apr. 1997.

[8] F. Torres, A. Camps, J. Bara, I. Corbella, and R. Ferrero, "On-board phase and modulus calibration of large aperture synthesis radiometers: Study applied to MIRAS," IEEE Trans. Geosci. Remote Sens., vol. 34, no. 4, pp. 1000-1009, Jul. 1996.

[9] A. Camps, M. Zapata, I. Corbella, F. Torres, M. Vall-llossera, N. Duffo, V. Barrena, C. García, and F. Martín, "SMOS radiometric performance evaluation using SEPS: Evaluation of thermal drifts," in Proc. IGARSS, vol. 7, Anchorage, AK, Sep. 2004, pp. 4508-4511.

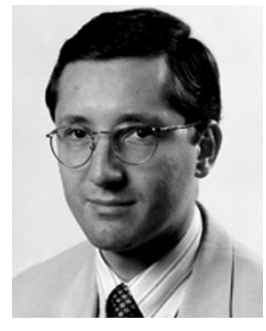

Adriano Camps (S'91-A'97-M'00-SM'02) was born in Barcelona, Spain, in 1969. He received the Telecommunications Engineering degree and the $\mathrm{Ph} . \mathrm{D}$. degree in telecommunications engineering in 1992 and 1996, respectively, both from the Polytechnic University of Catalonia (UPC), Barcelona, Spain.

From 1991 to 1992, he was with the ENS des Télécommunications de Bretagne, Bretagne, France, with an Erasmus Fellowship. In 1993, he joined the Electromagnetics and Photonics Engineering group, at the Department of Signal Theory and Communications, UPC, as an Assistant Professor, and since 1997 as an Associate Professor. In 1999, he was on sabbatical leave at the Microwave Remote Sensing Laboratory, University of Massachusetts, Amherst. His research interests are microwave remote sensing, with special emphasis in microwave radiometry by aperture synthesis techniques. He has performed numerous studies within the frame of European Space Agency SMOS Earth Explorer Mission. He is an Associate Editor of Radio Science.

Dr. Camps received the second national award of university studies in 1993, the INDRA award of the Spanish Association of Telecommunication Engineering to the best Ph.D. in 1997, the extraordinary Ph.D. award at the Universitat Politècnica de Catalunya in 1999, the First Duran Farell Award and the Ciudad de Barcelona Award, in 2000 and 2001, respectively, both for Technology Transfer, in 2002, the Research Distinction of the Generalitat de Catalunya for contributions to microwave passive remote sensing, in 2003, the Premi Nacional de Telecomunicacions (Generalitat de Catalunya) with the members of the Electromagnetics and Photonics Engineering group, and in 2004 a EURYI (European Young Investigator) Award. Also, as a member of the Microwave Radiometry Group at UPC, he received in 2000, 2001, and 2004 the 1st Duran Farell and the Ciudad de Barcelona Awards for Technology Transfeer, and the Salvà i Campillo Award of the Telecommunications (Engineering College of Catalonia) to the most innovative research project. He was Chair of Cal '01. He is editor of the IEEE Geoscience and Remote Sensing Newsletter and President-Founder of the IEEE Geoscience and Remote Sensing Society Spain Chapter.

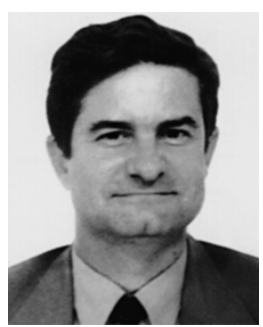

Ignasi Corbella (M'99) received the Telecommunications Engineering and Dr.Eng. degrees, both from Universitat Politècnica de Catalunya (UPC), Barcelona, Spain, in 1977 and 1983, respectively.

In 1976, he joined the School of Telecommunication Engineering in UPC as a Research Assistant in the Microwave Laboratory, where he worked on passive microwave integrated circuit design and characterization. During 1979, he worked at ThomsonCSF, Paris, France, on microwave oscillators design. In 1982, he became an Assistant Professor at UPC, an Associate Professor in 1986, and a Full Professor in 1993. He is currently teaching microwaves at the undergraduate level in UPC and has designed and taught graduate courses on nonlinear microwave circuits. During the school year 1998-1999, he worked at NOAA/Environmental Technology Laboratory, Boulder, CO, as a Guest Researcher, developing methods for radiometer calibration and data analysis. His research work in the Department of Signal Theory and Communications, UPC includes microwave airborne and satellite radiometry and microwave system design.

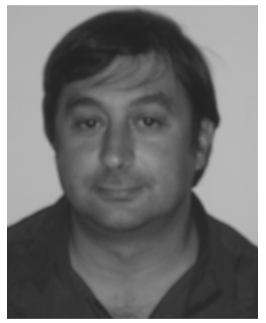

Francesc Torres (M'96) received the Ingeniero and Doctor Ingeniero degrees in telecommunication engineering from the Polytechnic University of Catalonia (UPC), Barcelona, Spain, in 1988 and 1992, respectively

In 1988-1989, he was a Research Assistant in the RF System Division, European Space Agency, Noordwijk, The Netherlands, devoted to microwave device testing and characterization. In 1989, he joined the Antenna-Microwave-Radar group, UPC, where he is currently an Associate Professor. His main research interests are focused on the design and testing of microwave systems and subsystems. He is currently engaged in research on interferometric radiometers devoted to earth observation.

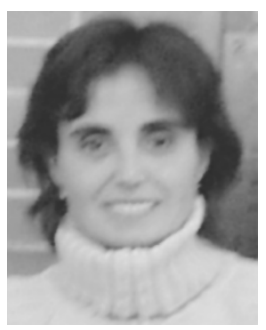

Núria Duffo (S'91-M'99) received the Telecommunication Engineer degree from the Polytechnic University of Catalonia (UPC), Barcelona, Spain, and the Doctor in Telecommunication Engineering from UPC, in 1990 and 1996, respectively.

Since 1997, she has been an Associate Professor at UPC. Her current research interests are numerical methods in electromagnetics, microwave radiometry, antenna analysis, and design.

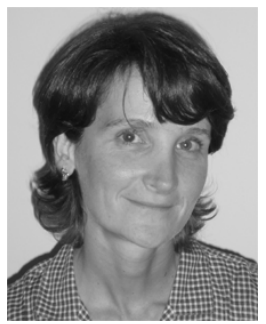

Mercè Vall-llossera (M'99) received the Senior Telecommunication Engineer and the Doctor Telecommunication Engineering degrees in 1990 and 1994, respectively, both from the Polytechnic University of Catalonia (UPC), Barcelona, Spain.

She has been lecturing and doing research at the Department of Signal Theory and Communications, UPC from 1990 until 1997 as an Assistant Professor and from 1997 until present as an Associate Professor. She spent a sabbatical year in Montreal with the scholarship of the "Programme Québécois de Bourses d'excellence" (1996-1997): "Stages de Formation postdoctorale au Québec pour jeunes diplômés étrangers." Her research interests include numerical methods in electromagnetism, microwave radiometry, antenna analysis, and design. Currently, her research is mainly related to the study of numerical methods applied to the sea surface emissivity and their characterization at L-band and the MIRAS/SMOS project.

Dr. Vall-llossera, along with the other members of the radiometry group at UPC, was awarded the "9th Edition of the Salvà i Campillo Award" in 2004, the "Primer Premio Duran Farell de Investigación Tecnológica" in 2002, and the "Primer Premio Ciutat de Barcelona d'Investigació Tecnològica" in 2001.

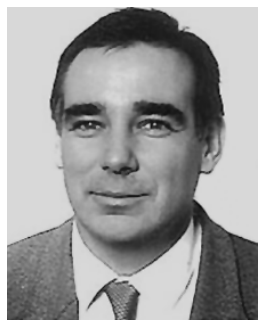

Manuel Martín-Neira (M'96) received the M.S. and $\mathrm{Ph} . \mathrm{D}$. degrees in telecommunication engineering in 1986 and 1996, respectively, from the School of Telecommunication Engineering, Polytechnical University of Catalonia, Catalonia, Spain.

From 1989 to 1992, he was was with GMV, a Spanish firm, where he was responsible for several projects for the European Space Agency (ESA) related to global positioning satellite navigation with applications to precise landing and attitude determination. Since 1992, with ESA, he has been in charge of the radiometer activities within the Payload, Equipment, and Technology Section. During this period, he has been responsible for the predevelopment technology activities related to the Microwave Imaging Radiometer with Aperture Synthesis (MIRAS) project. MIRAS (L-band Microwave Imaging Radiometer with Aperture Synthesis) is the only payload onboard the Soil Moisture and Ocean Salinity mission (SMOS), ESA's second Earth Explorer Opportunity Mission. He is currently the SMOS Instrument Principal Engineer.

Dr. Martín-Neira was awarded a Fellowship to work on radiometry at European Space Research and Technology Center (ESTEC), Noordwijk, The Netherlands, in 1988. 